Bull. Mater. Sci., Vol. 3, Number 4, December 1981, pp. 409-414. (c) Printed in India.

\title{
Van der Waals coefficients and cohesive energies of lead chalcogenides
}

\author{
CH SATYANARAYANA \\ Department of Physics, Arts and Science College (K.U.), Warangal 506 010, India .
}

MS received 7 January 1981

\begin{abstract}
The cohesive energies of $\mathrm{PbS} \mathrm{PbSe}$ and $\mathrm{PbTe}$, having $\mathrm{NaCl}$ type of crystal structure, are calculated using the generalized Huggins-Mayer form (GHM) for the Born repulsion energy. The van der Waals interactions (VDW) are estimated from the London and Mayer formulae and compared with those estimated from the SlaterKirkwood variational method. The cohesive energies calculated adopting the VDW coefficients calculated from the later method are in good agreement with the experimental values. The difference between the experimental cohesive energies and the calculated, assuming variational method, are $2.26,2.97$ and $3.75 \mathrm{eV}$ respectively for $\mathrm{PbS}, \mathrm{PbSe}$ and $\mathrm{PbTe}$ which are in good agreement with the reported values for the covalent bonding correction using Heitler-London-Lowdin method (HLL) which are respectively $2 \cdot 1,2 \cdot 9$ and $3 \cdot 3 \mathrm{eV}$ (Tanaka and Morita 1979).
\end{abstract}

Keywords. Lead chalcogenides; van der Waals interactions; variational method; Huggins-Mayer form of Born repulsion; cohesive energy; covalent bonding.

\section{Introduction}

The present paper attempts in evaluating the VDW coefficients and the cohesive energies of $\mathrm{PbS}, \mathrm{PbSe}$ and $\mathrm{PbTe}$ by the London and Mayer formulae (Tosi 1964) for VDW coefficients assuming electronic polarizabilities and the excitation energies (for the anions electron affinities and for the cation the 3rd ionization potential) for the ions. The VDW coefficients are also computed from the variational method (Margenau 1971, Narayan 1977 and Jain and Jaishankar 1979). The repulsive parameters for each crystal are calculated employing the two sets of VDW coefficients, adopting Huggins-Mayer form for the determination of Born repulsive energy. The cohesive energies calculated by both the methods are compared with the experimental values reported. It is observed that the cohesive energies calculated from the variational method are in good agreement with the experimental values. In lead chalcogenides the VDW interactions are found to contribute significantly to the cohesion in these crystals.

\section{The cohesive energy equation}

The cohesive energy of ionic crystalline solids can be written as:

$$
W_{L}(\mathrm{kcal} / \mathrm{mole})=10^{-10}(N / J)(\phi+\psi),
$$




$$
\begin{aligned}
& \phi=-a(z e)^{2} / r-C / r^{6}-D / r^{8}+b \beta_{+-} M \exp \left[\left(r_{+}+r_{-}-r\right) / \rho\right] \\
& +\frac{M^{\prime}}{2} b\left\{\beta_{++} \exp \left[\left(2 r_{+}-\sqrt{2 r}\right) / \rho\right]+\beta_{--} \exp \left[\left(2 r_{-}-\sqrt{2 r}\right) / \rho\right]\right\}
\end{aligned}
$$

The symbols in these equations have the same significance as reported by Huggins and Sakamoto (1957) and the zero- point energy per molecule, $\psi=9 / 4 h v_{\max }$, is computed from the Debye temperature. The Pauling coefficients, $\beta_{i j}=1+\frac{Z_{i}}{n_{i}}+\frac{Z_{j}}{n_{j}}$ where $z$ 's are the valencies and $n$ 's are the number of outer shell electrons of the $i$ th and $j$ th ions, and it is assumed that $\beta_{+-}=1, \beta_{++}=1.5$ and $\beta_{--}=0.5$.

\section{Van der Waals interactions}

\subsection{Van der Waals coefficients using London and Mayer formulae}

The VDW coefficients $C$ and $D$ can be calculated from the pair of interaction coefficients $c_{i j}$ and $d_{i j}$ given by

$$
\begin{aligned}
& c_{i j}=\frac{3}{2} \alpha_{i} a_{j} \frac{E_{l} E_{j}}{E_{i}+E_{j}}, \\
& d_{i j}=\frac{9}{4} \frac{c_{i j}}{e^{2}}\left[\frac{a_{i} E_{t}}{P_{t}}+\frac{a_{j} E_{j}}{P_{j}}\right],
\end{aligned}
$$

where the $a$ 's are the polarizabilities, the $E$ 's are the excitation energies of the ions and the $P$ 's are the effective number of outer shell electrons. Assuming the $P$ 's each equal to 5.5 (Huggins and Sakamoto 1957) the $c$ 's and $d$ 's are calculated and thus $C$ and $D$ are calculated using the appropriate lattice sums (Tosi 1964). The results are shown in table 2 from the data of table 1.

\subsection{Van der Waals coefficients by variational method}

The pair interaction coefficients can also be expressed, following the variational method based on the Slater-Kirkwood variational method (Margenat 1971; Narayan 1977; Jain and Jaishankar 1979), as

$$
\begin{aligned}
& c_{i j}=3 / 2 \frac{e h}{m^{1 / 2}} a_{i} a_{j} /\left[\left(\alpha_{i} / N_{i}\right)^{1 / 2}+\left(\alpha_{j} / N_{j}\right)^{1 / 2}\right], \\
& d_{i j}=\frac{27}{8 m} \hbar^{2} \alpha_{i} \alpha_{j}\left[\left(\alpha_{i} / N_{i}\right)^{1 / 2}+\left(a_{j} / N_{j}\right)^{1 / 2}\right]^{2} /\left[\frac{\alpha_{i}}{N_{i}}+\frac{20}{3} \frac{a_{i} a_{j}}{N_{i} N_{j}}+\frac{a_{j}}{N_{j}}\right],
\end{aligned}
$$

where $N$ 's are the effective number of electrons in the two ions participating in the interactions and are taken from Scott and Scheraga 1965. The VDW coefficients calculated from equations (5) and (6) are shown in table 2. 
Table 1. Crystal data for lead chalcogenides at room temperature.

\begin{tabular}{|c|c|c|c|}
\hline & $\mathrm{PbS}$ & $\mathrm{PbSe}$ & PbTe \\
\hline Interionic distance $r(\AA)$ & $2.968(a)$ & $3 \cdot 074$ (a) & $3 \cdot 225$ (a) \\
\hline \multicolumn{4}{|l|}{ Elastic constants $\left(10^{11}\right.$ dynes $\left./ \mathrm{cm}^{2}\right)$} \\
\hline$c_{11}$ & $12 \cdot 40$ (a) & $12 \cdot 37(\mathrm{a})$ & $10 \cdot 72$ (a) \\
\hline$c_{12}$ & $3 \cdot 30$ (a) & $1.98(a)$ & 0.768 (a) \\
\hline$c_{44}$ & $2 \cdot 30$ (a) & $1 \cdot 59$ (a) & 1.30 (a) \\
\hline Compressibility $K\left(10^{-12} \mathrm{~cm}^{2} /\right.$ dyne $)$ & $1 \cdot 580^{*}$ & $1 \cdot 850^{*}$ & $2 \cdot 450 *$ \\
\hline Polarizability $\left(\AA^{3}\right)$ & $\begin{array}{l}5 \cdot 460(b) \\
4 \cdot 90(c)\end{array}$ & $7 \cdot 210(b)$ & $10 \cdot 65(b)$ \\
\hline Electron affinity $E$ (kcal/mole) & $99 \cdot 0$ (d) & $117 \cdot 0(d)$ & $97 \cdot 0$ (d) \\
\hline 3rd ionization energy of $\mathrm{Pb}(\mathrm{kcal} / \mathrm{mole})$ & $736.4(\mathrm{e})$ & & \\
\hline Volume thermal expansion $\beta\left(10^{-4} /{ }^{\circ} \mathrm{C}\right)$ & $0.608(f)$ & $0.582(f)$ & 0.594 (f) \\
\hline $\begin{array}{ll}\text { Pauling crystal radii }(\AA) & r_{-} \\
r_{+}\end{array}$ & $\begin{array}{l}1 \cdot 84(\mathrm{~g}) \\
1 \cdot 21(\mathrm{~g})\end{array}$ & $1.98(\mathrm{~g})$ & $2 \cdot 21(\mathrm{~g})$ \\
\hline Debye temperature $\theta\left({ }^{\circ} \mathrm{K}\right)$ & $227 \cdot 0$ (i) & $138 \cdot 0$ (i) & $125 \cdot 0$ (i) \\
\hline Effective number of electrons $\frac{N_{-}}{N_{+}}$ & $\begin{array}{l}15 \text { (h) } \\
49 \text { (h)@ }\end{array}$ & 21 (h) & 29 (h) \\
\hline
\end{tabular}

*Compressibility is computed from the elastic data of Jogi and Tripathi 1975.

(a) $N_{+}$, the effective number of electrons for the lead ion which contribute to the polarization is taken from the graph of Scott and Scheraga (1965) by extrapolation of the graph while $N_{-}$are directly read from it.

(a) Jogi and Tripathi 1975, (b) Agrawal et al 1978, (c) Tessman et al 1953, (d) Huggins and Sakamoto 1957, (e) Harvey and Porter 1972, (f) Novikova and Abikosov 1964, (g) Dekker 1969, (h) Scott and Scheraga 1965, (i) Parkinson and Quarrington 1954.

\section{Born repulsion parameters}

The repulsion parameters for the Huggins-Mayer form of the Born repulsive energy can be determined from the solid-state data in standard thermodynamic conditions by solving the equation for the cohesive energy together with the equation of state of various crystals and its volume derivative at constant pressure in the vibrational Hilderbrand form:

$$
\begin{aligned}
& r=r_{+}+r_{-}+\rho \ln \left\{6 \beta_{+-} b \frac{r}{\rho}\right. \\
& \left.\frac{1+\sqrt{2}\left[\frac{\beta_{++}}{\beta_{+-}} \exp \left(\frac{r_{+}-r_{-}}{\rho}\right)+\frac{\beta_{--}}{\beta_{+-}} \exp \left(\frac{r_{-}-r_{+}}{\rho}\right)\right] \exp \left(\frac{(1-\sqrt{ } 2) r}{\rho}\right)}{\tau}\right\}, \\
& \frac{\left(\frac{r}{\rho} \frac{\tau}{\sigma}-1\right)}{\left(\sqrt{2} \frac{r}{\rho} \frac{\tau}{\sigma}-1\right)}=-\sqrt{2}\left[\frac{\beta_{++}}{\beta_{+-}} \exp \left(\frac{r_{+}-r_{-}}{\rho}\right)+\frac{\beta_{-}}{\beta_{+-}} \exp \left(\frac{r_{-}-r_{+}}{\rho}\right)\right] \\
& \exp \left[\frac{(1-\sqrt{2}) r}{\rho}\right],
\end{aligned}
$$


Table 2. The calculated values of the VDW coefficients, repulsion parameters and the cohesive energies [the upper number is the calculated value using equations (3) and (4) and the lower one is obtained by using variational method equations (5) and (6)].

\begin{tabular}{|c|c|c|c|c|}
\hline & & $\mathrm{PbS}$ & PbSe & PbTe \\
\hline VDW ' $c$ ' coefficients & $c_{++}$ & $\begin{array}{l}921 \cdot 196 \\
955 \cdot 074\end{array}$ & $\begin{array}{l}921 \cdot 196 \\
955 \cdot 074\end{array}$ & $\begin{array}{l}921 \cdot 196 \\
955 \cdot 074\end{array}$ \\
\hline \multirow[t]{3}{*}{$\left(10^{-80} \mathrm{erg} / \mathrm{cm}^{8}\right)$} & $c_{--}$ & $\begin{array}{l}151 \cdot 768 \\
621 \cdot 549\end{array}$ & $\begin{array}{r}316 \cdot 890 \\
1115 \cdot 973\end{array}$ & $\begin{array}{r}573 \cdot 214 \\
2354 \cdot 316\end{array}$ \\
\hline & $\boldsymbol{c}_{+-}$ & $\begin{array}{l}243.287 \\
736.944\end{array}$ & $\begin{array}{l}371 \cdot 667 \\
992 \cdot 070\end{array}$ & $\begin{array}{c}466 \cdot 073 \\
1423 \cdot 9210\end{array}$ \\
\hline & $C$ & $\begin{array}{l}2575 \cdot 595 \\
6284 \cdot 535\end{array}$ & $\begin{array}{l}3569 \cdot 643 \\
8413 \cdot 779\end{array}$ & $\begin{array}{r}4423 \cdot 820 \\
12380 \cdot 574\end{array}$ \\
\hline \multirow[t]{4}{*}{$\begin{array}{l}\text { 'd' coefficients } \\
\left(10^{-76} \mathrm{erg} / \mathrm{cm}^{8}\right)\end{array}$} & $d_{t++}$ & $\begin{array}{r}8191 \cdot 809 \\
456 \cdot 161\end{array}$ & $\begin{array}{r}8191 \cdot 809 \\
456 \cdot 161\end{array}$ & $\begin{array}{r}8191 \cdot 809 \\
456 \cdot 161\end{array}$ \\
\hline & $d_{-}$ & $\begin{array}{l}204 \cdot 839 \\
566 \cdot 384\end{array}$ & $\begin{array}{l}658.790 \\
987.639\end{array}$ & $\begin{array}{l}1459 \cdot 339 \\
2154 \cdot 888\end{array}$ \\
\hline & $d_{+-}$ & $\begin{array}{r}1243 \cdot 769 \\
529 \cdot 209\end{array}$ & $\begin{array}{r}2038 \cdot 873 \\
656 \cdot 288\end{array}$ & $\begin{array}{l}2665 \cdot 581 \\
1047 \cdot 069\end{array}$ \\
\hline & $D$ & $\begin{array}{r}11003 \cdot 329 \\
3661 \cdot 537\end{array}$ & $\begin{array}{r}16071 \cdot 425 \\
4611.066\end{array}$ & $\begin{array}{r}20243 \cdot 245 \\
7479 \cdot 706\end{array}$ \\
\hline Repulsion parameters & $\rho(\AA)$ & $\begin{array}{l}0.402 \\
0.427\end{array}$ & $\begin{array}{l}0.431 \\
0.456\end{array}$ & $\begin{array}{l}0.485 \\
0.505\end{array}$ \\
\hline \multicolumn{2}{|c|}{$b\left(10^{-12} \mathrm{erg} / \mathrm{molecule}\right)$} & $\begin{array}{l}1.279 \\
1.856\end{array}$ & $\begin{array}{l}1 \cdot 331 \\
2 \cdot 053\end{array}$ & $\begin{array}{l}1.053 \\
1.534\end{array}$ \\
\hline Madelung energy $W_{e}$ & (kcal/mole) & $-781 \cdot 901$ & -754.939 & -719.591 \\
\hline \multicolumn{2}{|c|}{$\begin{array}{l}\text { Dipole-dipole interaction } \\
\text { energy } W_{d d}(\mathrm{kcal} / \mathrm{mole})\end{array}$} & $\begin{array}{r}-54 \cdot 238 \\
-132 \cdot 342\end{array}$ & $\begin{array}{r}-60 \cdot 899 \\
-188 \cdot 137\end{array}$ & $\begin{array}{r}56 \cdot 601 \\
-158 \cdot 407\end{array}$ \\
\hline \multicolumn{2}{|c|}{$\begin{array}{r}\text { Dipole-quadrupole interaction } \\
\text { energy } W_{d q}(\mathrm{kcal} / \mathrm{mole})\end{array}$} & $\begin{array}{l}-26 \cdot 304 \\
-\quad 8 \cdot 753\end{array}$ & $\begin{array}{r}-29 \cdot 016 \\
-\quad 8 \cdot 325\end{array}$ & $\begin{array}{r}24.903 \\
-\quad 9.202\end{array}$ \\
\hline \multicolumn{2}{|c|}{ Repulsion energy $W_{b}(\mathrm{kcal} / \mathrm{mole})$} & $\begin{array}{l}152 \cdot 127 \\
221 \cdot 517\end{array}$ & $\begin{array}{l}175 \cdot 923 \\
269 \cdot 440\end{array}$ & $\begin{array}{l}171 \cdot 356 \\
248 \cdot 623\end{array}$ \\
\hline \multicolumn{2}{|c|}{ Zero point energy $W_{0}(\mathrm{kcal} / \mathrm{mole})$} & 1.637 & 0.992 & 0.899 \\
\hline \multicolumn{2}{|c|}{$\begin{array}{l}\text { Cohesive energy } W_{1}(\mathrm{kcal} / \mathrm{mole}) \\
\left(W_{1}=W_{e}+W_{d d}+W_{d q}+W_{0}+W_{b}\right)\end{array}$} & $\begin{array}{l}-708 \cdot 679 \\
-699 \cdot 842\end{array}$ & $\begin{array}{l}-667.919 \\
-680 \cdot 968\end{array}$ & $\begin{array}{l}-628 \cdot 840 \\
-637 \cdot 678\end{array}$ \\
\hline
\end{tabular}

where $\quad \tau=\frac{a(z e)^{2}}{r}+\frac{6 C}{r^{6}}+\frac{8 D}{r^{8}}-\frac{6 r^{3} \beta T}{K}$,

$$
\begin{aligned}
& \sigma=\underset{r}{\overline{2 a(z e)^{2}}}+\frac{42 C}{r^{6}}+\frac{72 D}{r^{8}}+\frac{18 r^{3}}{K} F(T, P) \\
& F(T, P)=1+\frac{T}{K}\left[\left(\frac{\partial K}{\partial T}\right)_{P}+\frac{\beta}{K}\left(\frac{\partial K}{\partial P}\right)_{T}\right]+\frac{2}{3} \beta T
\end{aligned}
$$


$\tau$ and $\sigma$ are computed using the two sets of calculated values of $C$ and $D$ from (9) and (10). While evaluating $\sigma F(T, P)$ is assumed to be unity. $\rho$ is determined by assuming Pauling crystal radii for the ions using (8) and then the energy parameter $b$ is determined from (7) for each crystal. The repulsion parameters and the various energy terms obtained by the two methods viz. using (3) and (4), and by the variational method equations (5) and (6), are shown in table 2.

\section{Discussion}

The interaction coefficients $d$ 's obtained by (3) and (4) are seen to be larger compared to those obtained by the variational method, while the $c$ 's are relatively smaller, as is evident from table 2. However, it has been earlier reported (for a good review see Tosi 1964; Waddington 1959 and Jain and Jaishankar 1979) that the former method is subjected to considerable uncertainties. The justification in the reliability of the calculated values of $c$ 's and $d$ 's from (5) and (6) is that the assumptions regarding the excitation energies is removed. The elimination of $E^{\prime}$ 's from (3) with the help of the one level formula for polarizability $a=N e^{2} h^{2} / m E^{2}$ leads to (5) and a similar approach to (6). From the calculations it is seen that the van der Waals energy significantly contributes to the cohesive energy of these crystals. The Born repulsion coefficients calculated on the basis of variational method $\rho$ and $b$ are larger compared to those obtained from London and Mayer formulae. $\rho$ varies from 0.427 to 0.505 from sulphide to telluride.

Comparison of the cohesive energies of lead chalcogenides calculated from (1) with the experimental values shows that the difference between experimental and the theoretical one on the basis of ionic approximation increased trom $\mathrm{PbS}$ to $\mathrm{PbTe}$. Thus from the difference it can be said that $\mathrm{PbS}$ is more ionic and the covalent contribution increases from $\mathrm{PbS}$ to $\mathrm{PbTe}$.

Recently the cohesive energies of $\mathrm{PbS}, \mathrm{PbSe}$ and $\mathrm{PbTe}$ have been reported by Tanaka and Morita (1979) which are shown in table 3. His calculations are based on the Heitler-London-Lowdin treatment modified so as to include the effect of covalent bonding. The covalent bonding correction for $\mathrm{PbS}, \mathrm{PbSe}$ and PbTe on the basis of HLL treatment is given in table 3 , which is in good

Table 3. Cohesive energies of $\mathrm{PbS}, \mathrm{PbSe}$ and $\mathrm{PbTe}$.

\begin{tabular}{|c|c|c|c|c|c|}
\hline \multirow{2}{*}{ Crystal } & \multicolumn{2}{|c|}{ Present work } & \multicolumn{2}{|c|}{ Tanaka and Morita 1979} & \multirow[b]{2}{*}{$\begin{array}{c}W_{L} \text { (Expt.)- } \\
W_{L} \text { (variationa } \\
\text { method) } \\
(\mathrm{eV})\end{array}$} \\
\hline & $\begin{array}{c}\text { London Mayer } \\
\text { formulae for } \\
\text { VDW } \\
\text { (kcal/Mole) }\end{array}$ & $\begin{array}{l}\text { Variational } \\
\text { method } \\
\text { (kcal/Mole) }\end{array}$ & $\begin{array}{c}\text { Experimental } \\
\text { (as reported) } \\
\text { (kcal/Mole) }\end{array}$ & $\begin{array}{c}\text { Covalent } \\
\text { bonding } \\
\text { correction } \\
\text { based on the } \\
\text { quantum theory } \\
(\mathrm{eV})\end{array}$ & \\
\hline $\mathrm{PbS}$ & $-708 \cdot 679$ & $-699 \cdot 842$ & $-751 \cdot 854$ & $2 \cdot 1$ & $2 \cdot 26$ \\
\hline $\mathrm{PbSe}$ & $-667 \cdot 919$ & -680.968 & $-749 \cdot 548$ & $2 \cdot 9$ & $2 \cdot 97$ \\
\hline $\mathrm{PbTe}$ & $-628 \cdot 840$ & $-637 \cdot 678$ & $-724 \cdot 178$ & $3 \cdot 3$ & $3 \cdot 75$ \\
\hline
\end{tabular}


agreement with the difference of cohesive energies calculated on the basis of the variational method in the determination of $c$ 's and $d$ 's (present calculations) and the experimental values.

Finally, the Huggins-Mayer form of the Born repulsion which assumes a constant value of $\rho$ for different pairs of ions leads to the cohesive energies which are in good agreement with those evaluated on the basis of quantum theory (HLL-treatment) on an ionic approximation, when the repulsion parameters for each crystal are evaluated from the calculated values of the VDW coefficients on the basis of variational method.

\section{Acknowledgement}

The author thanks Dr D B Sirdeshmukh for his encouragement.

\section{References}

Agrawal S C, Sharma H P and Jai Shankar 1978 Indian J. Pure Appl. Phys. 16438

Dekker A J 1969 Solid state physics Macmillan)

Huggins M L and Skamoto Y 1957 J. Phys. Soc. Jpn. 12241

Harvey K B and Porter G B 1972 Introduction to physical inorganic chemistry Addison-Wesley) 3rd Ed.

Jain V C and Jai Shankar 1979 Pramana 1331

Jogi S and Tripathi B B 1975 Indian J. Pure Appl. Phys. 13427

Margenau H 1971 Intermolecular forces (New York: Pergamon Press)

Narayan R 1977 J. Phys. Chem. Solids 381097

Novikova S I and Abikosov N Kh 1964 Sov. Phys. Solid State 5

Parkinson D H and Quarrington J E 1954 Proc. Phys. Soc. A67 567

Scott R A and Scheraga H A 1965 J. Chem. Phys. 422209

Tanaka H and Morita A 1979 J. Phys. Soc. Jpn. 46523

Tessman J, Kahn A and Shockley W 1953 Phys. Rev. 92890

Tosi M P 1964 Solid state physics Vol. 16 (New York: Academic Press)

Tosi M P and Fumi F G 1964 J. Phys. Chem. Solids 2545

Waddington T C 1959 Advances in inorganic chemistry and radiochemistry Vol. 1 (New York: Academic Press) 